\title{
CONTROL PARAMETER OPTIMIZATION-BASED MACHINING CONTROL TECHNOLOGY OF STATE-OF-THE ART COMPUTER NUMERICAL CONTROL MACHINE TOOLS
}

\author{
Mulin $\mathrm{Hu}$ \\ Hefei Technology College, Hefei, 230012, China. \\ Email: humulinhftc@126.com
}

\begin{abstract}
In order to improve the accuracy, reliability and efficiency of computer numerical control (CNC) machine tools, first, according to the working principle of servo motor and related physical relations, the mathematical model of servo system is established. Moreover, the mathematical model is used to establish the three-closed loop simulation structure of servo. Then, according to the simulation structure, a parameter optimization algorithm of CNC machine tool servo system based on improved particle swarm optimization (PSO) algorithm is proposed. Compared with the previous PSO algorithm, the PSO algorithm used has two improvements. First, it introduces the nonlinear dynamic inertia weight coefficient, and constructs the functional relationship between accelerated factor and inertia weight. Second, it introduces the extreme perturbation operator to increase the search range of particles. Moreover, the improved PSO algorithm is used to optimize the scale factor parameters in the regulator. The experimental results show that the dynamic performance of CNC machine tool servo system has been improved to a certain extent. Compared with the Proportion Integration Differentiation (PID) parameters without tuning, the overshoot of the system is reduced and the robustness is improved. In addition, the tuning PID parameters are compared with those of crowd search algorithm (SOA), PSO and genetic algorithm (GA). The results show that the adjustment time to the stable error of the CNC machine tool servo system optimized by GA algorithm is longer than other algorithms, and the oscillation of the transition time is severer. The PID parameters of CNC machine tool servo system optimized by improved PSO algorithm are obviously better than those optimized by other algorithms. The system using this parameter has a short adjustment time and an overshoot of 0 . Therefore, the performance of the improved PSO algorithm is better than SOA, PSO and GA algorithm. The proposed algorithm provides a new idea for intelligent algorithm to solve the control parameter optimization problem of CNC machine tools.
\end{abstract}

Keywords: Servo System; Optimization Criterion; Computer Numerical Control Machine Tools; Simulation.

\section{Introduction}

Computer numerical control (CNC) machine tool is an important equipment for precision machining of complex curved parts. The linear axis of CNC machine usually adopts the direct drive technology with good dynamic response and fast running speed. Direct drive technology adopts many kinds of interpolation technology to meet the requirements of machining complex workpiece with high precision and high surface finish [1]. In the actual production process, the driving parameters and system parameters of the servo system can meet the general precision requirements of the parts processing before the CNC machine leaves the factory. When there is gear machining with high precision and surface finish requirements, because the parameters of servo motor drive control system are not optimized in real time, the matching between servo motor drive system and load is not ideal [2], which will result in the phenomenon that the surface finish of machined parts cannot meet the requirements, machine bed jitter and noise will occur. Therefore, it is very important to optimize the control parameters of servo system. In the research of the servo control system of machine tool, many researchers in China and foreign countries have done a lot of work.

In order to solve the problem that the controller parameters cannot be adjusted after the installation of the servo system of launch vehicle, Tian et al. (2021) designed the parameter adjustment method of the servo system controller parameters based on the optimization method of genetic algorithm (GA). The scale, notch frequency and damping factor were used as adjustment variables. The adjusted error integral criterion module was the error criterion. 
The experimental results of servo system simulation test bench show that the proposed method can effectively optimize the parameters of servo system controller and improve the quality of servo system [3]. Yue et al. (2020) believed that advanced CNC machine tools are more and more important than ever before, and the problem of fault diagnosis of CNC machine tools is becoming more and more important. Traditional failure mode, influence analysis and critical analysis were combined with fuzzy theory to analyse the faults of the spindle system of CNC machine tools to avoid unnecessary faults and realize the safe and reliable operation of the equipment. In addition, the critical failure modes of key components and spindle system on CNC machine tools that need special attention were determined [4].

Vorkapi et al. (2020) developed a three-axis rapid prototyping CNC machine tool with two translation and one rotation axes by taking LinuxCNC system as control platform and integrated virtual machine (IVM) as digital twin. Moreover, in the environment of management software computer aided manufacturing (CAD) / computer aided manufacturing (CAM), a complete configuration was made. Finally, the correctness of the mechanical design was verified [5]. Yang et al. (2020) believed that with the development of modern manufacturing industry, the requirements for the performance of CNC machine tools are higher and higher; for high precision CNC machine tools, vibration in high-speed machining is an important factor affecting machining accuracy; as an important part of CNC machine tool, the dynamic characteristics of feed driving system have a great influence on the machining performance. Ball screw drive system is widely used in most CNC machines. In the process of high-speed machining, the vibration of the ball screw drive system will affect the stability of the control system and the machining accuracy of the CNC machine; therefore, further study on the dynamic characteristics and vibration control methods of ball screw transmission system is of great significance to improve the mechanical performance.

The research status of vibration analysis and control methods of feed transmission system was reviewed. System modelling, parameter identification and vibration control technology related studies were classified and summarized. The advantages and disadvantages of different methods were discussed and compared. The linear variable parameter modelling method and control technology of ball screw drive system were introduced in detail. Finally, based on the existing research, the related research prospects were systematically put forward, which are of great significance for the development of vibration control technology of CNC machine tool feed drive system [6]. Chang (2018) proposed a nonlinear control technology of AC power regulation for ultra-precision machining of steel materials. This technology combines the advantages of finite time tracking control and cuckoo search algorithm (CSA). FTTC (finite time tracking control) allows the system to be insensitive to the uncertainties of the system and to converge in finite time. It is a noteworthy fact that flutter occurs under high dynamic loads. Under the condition of AC power supply, chatter will cause large distortion of output voltage, which leads to instability and unreliability of ultra-precision machining of steel. Therefore, CSA is used to reduce chatter so that AC power regulation can provide robust performance for ultra-precision machining of steel materials. Because the control technology is easier to implement than before, the tracking accuracy is high and the calculational-complexity algorithm is low, the experiment shows the low output voltage total harmonic distortion and fast response. This exploration is helpful for researchers to study the ultra-precision machining of steel materials [7].

However, at present, the Proportion Integration Differentiation (PID) tuning of CNC machine tools mostly depends on the empirical method. There are many problems in PID parameters tuning with empirical method, such as long tuning time, and poor performance of tuning results. For this reason, particle swarm optimization (PSO) algorithm is improved, and an optimized PID parameter optimization method of CNC machine tool feed drive servo system based on improved PSO algorithm is proposed.

\section{PID Control Theory and Mathematical Modelling of Numerical Control AC Servo System 2.1 PID Control Principle}

At present, PID regulator is the most widely used regulator. The control law of PID regulator is proportional, integral and differential control $[8,9]$. PID regulator has the characteristics of simple structure, high stability and easy adjustment. Figure 1 is the structure diagram of PID regulator.

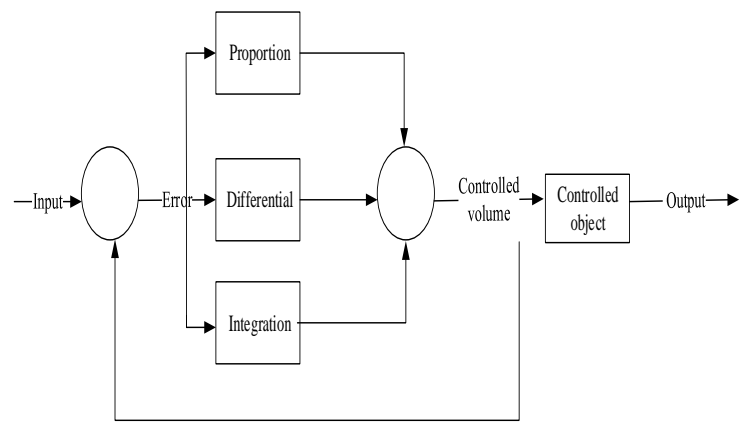

Figure 1: PID structure diagram 
In the continuous servo control system, the relationship between output signal and input signal of PID controller can be written in the form of equation (1).

$$
G(s)=\frac{U(s)}{E(s)}=K_{P}\left(1+\frac{1}{T_{i} s}+T_{d} s\right)
$$

$$
u(t)=K_{P} \operatorname{errot}(t)+\frac{1}{T_{i}} \int_{0}^{t} \operatorname{errot}(t) d t+T_{d} \frac{\operatorname{derrot}(t)}{d t}
$$

In (2), $K_{P}$ is proportional control and errot is steady-state error. The sampling period of the system is set to $T$, and the idea of calculus is used to
In (1), $K_{P}$ is the proportional coefficient, $T_{i}$ is the integral time constant and $T_{d}$ is the differential time constant.

The digitization of PID regulator is to discrete the PID in analogue system. Equation (2) is the form of PID equation of continuous system.

$$
u(K)=K_{P} \operatorname{errot}(K)+\frac{T}{T_{i}} \sum_{i=0}^{K} \operatorname{errot}(i-1)+\frac{T_{d}}{T_{0}}[\operatorname{errot}(K)-\operatorname{errot}(k-1)]
$$

The regulation mode of PID regulator can be divided into proportional control $\left(K_{P}\right)$, integral control $\left(T_{i}\right)$, and differential control $\left(T_{d}\right) . K_{P}$ control is the most widely used control mode, and the output signal of $K_{P}$ controller is inversely proportional to the input error signal. When the ratio coefficient $K_{P}$ increases, the error of the system will be amplified and the response of the system will be sensitive $[10,11]$. When the system tends to be stable, increasing $K_{P}$ can reduce the steady-state error, but it cannot eliminate the error completely. When $K_{P}$ increases to a certain extent, the system will have the phenomenon of oscillation $[12,13]$. Integral control means that the output signal of the controller is proportional to the integral of the input signal. The frequency of oscillation increases with the decrease of $T_{i}$ value. The increase of $T_{i}$ value will reduce the effect on the system performance. $T_{d}$ control is that the output signal of the controller is proportional to the error change rate of the input error signal. In the actual engineering, $T_{d}$ often works with $T_{i}$ and $K_{P}$. Its main purpose is to improve the stability and dynamic characteristics of the closed-loop system $[14,15]$.

The performance index of AC servo system mainly includes time domain index and frequency domain index. Specifically, it includes the maximum overshoot $M_{P}$ which is used to describe that the output exceeds the maximum offset corresponding to the final value of the input during the transient period; the peak time $T_{P}$ when the maximum overshoot occurs; the rise time $T_{r}$ which is the time when the output reaches the input value for the first time in the transient process; the adjustment time $T_{s}$ of the time that the deviation between the output value and the final value corresponding to the input reaches the allowable range; the error between the expected value and the actual value of steady-state response, which is steady-state error errot [16,17].

\subsection{Composition of CNC Machine Tools}

CNC machine tool is composed of digital control system, servo drive system and machine hardware. Among them, the hardware of machine tool includes transmission chain, worktable and processing auxiliary parts; the servo drive system includes servo motor and servo driver, which is the core of CNC machine tool $[18,19]$. For CNC machine tools with superior performance, the control system used is generally a fast response, accurate calculation, advanced digital control system $[20,21]$. The CNC system includes digital processing unit, servo drive controller, input and output interface, operation panel, display unit and other components. It can realize the calculation and storage of all the data of the machine tool, and store the processing program of the machine tool. It is the key to realize complex machining, motion control, rapid response and accurate calculation to send driving signal to servo motor after processing and calculation according to instructions [22].

\subsection{Mathematical Modelling of Main Components of Numerical Control AC Servo System}

There are many kinds of classification standards for servo system. The common classification methods are according to the regulation theory, according to the driving elements used, according to the feed drive and spindle drive, and according to the feedback comparison. According to the driving components used, it can be divided into stepping servo system, AC servo system and DC servo system 
[23,24]. Among them, the meaning of AC servo system is that the system contains AC asynchronous servo motor and permanent magnet synchronous servo motor. Compared with DC servo motor, AC servo motor has fewer defects, faster speed and higher output power. Therefore, AC servo system has been more and more widely used. From the relevant statistical data, it is not difficult to find that there are more than $80 \%$ AC servo systems used in the industrial field today [25]. At present, the current loop, speed loop and position loop of three closedloop PID control technology are widely used in the servo system of CNC machine tools. However, the efficiency of this PID parameter tuning method is not high, and the work experience of the tuning engineer is required to be high, because the design and parameter tuning of AC servo system is particularly important [26-28]. In order to analyse the dynamic and static quality of AC servo system, a mathematical model, usually ordinary differential equation, is needed to describe the dynamic physical law of the system.

The establishment of differential equation model can be divided into two steps.

1. Input and output variables of the system are determined. Then, the system is divided into several independent links according to its function, and the input and output signals of each link are determined.

2. For a given system, from the beginning of the system, the mathematical equations contained in the variables of the system are written out, and the necessary equations are sorted out. Finally, only the differential equations containing the input, output, and system component parameters are obtained. Figure 2 shows that the servo system is mainly composed of controller, inverter, servo motor, monitoring device and mechanical system. The three-loop control composed of current loop, speed loop and position loop are classic ways of $\mathrm{CNC}$ control structure.

Generally, position loop is the outer loop of servo system, while current loop and speed loop are the inner loop of servo system. Among them, the current loop and speed loop are generally completed by the driver, and the motion loop control is generally realized by the motion controller [29]. The function of current loop is to improve the response performance of the system and restrain the current interference inside the motor, so that the acceleration torque of AC servo system of CNC machine tool is large enough to ensure the safe operation of the system. The function of speed loop is to strengthen the anti-load ability of AC servo system of CNC machine tool and restrain the fluctuation of motion speed. The function of position loop is to ensure the dynamic and static performance of AC servo system of CNC machine tool better, and increase the stability of AC servo system of CNC machine tool. In order to better analyse the steadystate accuracy and static and dynamic quality of the system, the mathematical model of each component and link of the servo system is established. Figure 2 shows the structure of the three-loop control system.

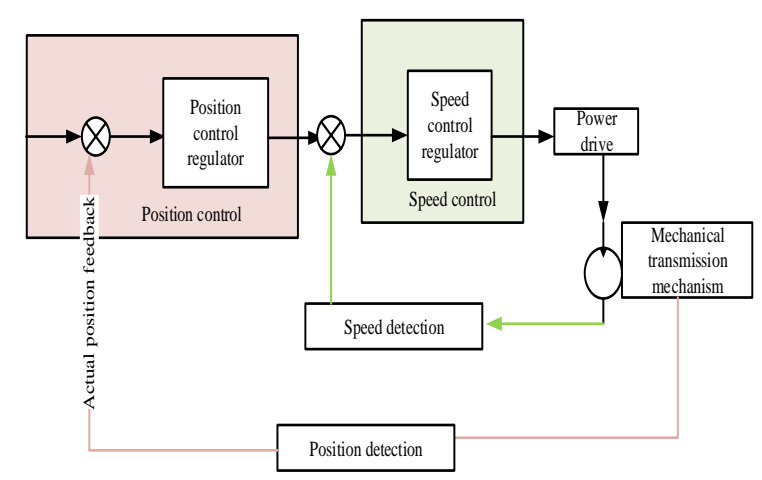

Figure 2: Structure of three-loop control system

AC servo motor is an important part of servo system, and its mathematical model is more complex, so in the process of dynamic research and simulation of servo system, AC servo motor is usually simplified. In the research area of this exploration, AC servo motor is simplified as permanent magnet synchronous machine. Equation (4) shows the electrical and mechanical equations of permanent magnet synchronous machine.

$$
\left\{\begin{array}{c}
u_{\mathrm{d}}=\mathrm{R}_{s} i_{d}+\mathrm{d} \varphi_{\mathrm{d}} / d_{t}-\omega_{e} \varphi_{q} \\
u_{q}=R_{\mathrm{s}} \mathrm{i}_{\mathrm{q}}+\mathrm{d} \varphi_{\mathrm{d}} / d_{t}+\omega_{e} \varphi_{d} \\
\varphi_{d}=L_{\mathrm{d}} \mathrm{i}_{d}+\varphi_{\mathrm{r}} \\
\varphi_{\mathrm{q}}=\mathrm{L}_{\mathrm{q}} \mathrm{i}_{\mathrm{q}}
\end{array}\right.
$$

In (4), $u_{\mathrm{d}}, u_{q}, i_{d}$ and $\mathrm{i}_{\mathrm{q}}$ are stator voltage and current in $\mathrm{d}$ and q coordinate axes respectively; $L_{\mathrm{d}}$ and $\mathrm{L}_{\mathrm{q}}$ are direct axis and quadrature axis inductance; $\varphi_{\mathrm{d}}$ and $\varphi_{\mathrm{q}}$ are stator flux linkage in $d, q$ coordinate axes; $\mathrm{R}_{s}$ and $\omega_{e}$ are stator resistance and electric angle.

Equation (5) is the motion equation of the motor.

$$
\mathrm{d} \omega_{\mathrm{r}} / d_{t}=\left(\mathrm{T}_{\mathrm{e}}-\mathrm{T}_{m}-\mathrm{B} \omega_{r}\right) / \mathrm{J}
$$

Equation (6) is the motor torque equation.

$$
T_{e}=3 P_{\mathrm{n}}\left[\varphi_{r} \mathrm{i}_{q}+\left(\mathrm{L}_{\mathrm{d}}-\mathrm{L}_{q}\right) \mathrm{i}_{d} \mathrm{i}_{q}\right] / 2(6)
$$

In equations (5) and (6), $\mathrm{J}$ is the moment of inertia, $\mathrm{B}$ is friction coefficient, $\omega_{r}$ is the 
mechanical angle, and $P_{\mathrm{n}}$ is the pole logarithm of the motor.

\subsection{PSO and its Improvement}

PSO is an algorithm based on group search, which can search the optimal solution by simulating the migration and clustering of birds in the process of foraging. PSO algorithm updates the velocity and position of particles by tracking the local optimal solution and global optimal solution in the iterative process. Equations (7) and (8) are the update equations of particle velocity and position respectively.

$$
\begin{aligned}
& v_{i d}^{k+1}=w^{*} v_{i d}^{k}+c_{1} r_{1}^{*}\left(p_{i d}^{k}-x_{i d}^{k}\right)+c_{2} r_{2}^{*}\left(g_{i d}^{k}-x_{i d}^{k}\right) \\
& x_{i d}^{k+1}=x_{i d}^{k}+v_{i d}^{k+1}
\end{aligned}
$$

In (7) and (8), $w$ is the inertia weight coefficient, $c_{1}$ and $c_{2}$ are the learning factors, and $r_{1}$ and $r_{2}$ are random numbers greater than 0 and less than 1 ; $v_{i d}^{k}$ is the flight speed of particle $i$ in the K-th iteration. $x_{i d}^{k}$ is the position of particle $i$ in the K-th iteration. $p_{i d}^{k}$ is the local optimal solution and $g_{i d}^{k}$ is the global optimal solution. Figure 3 shows the iterative process of PSO algorithm.

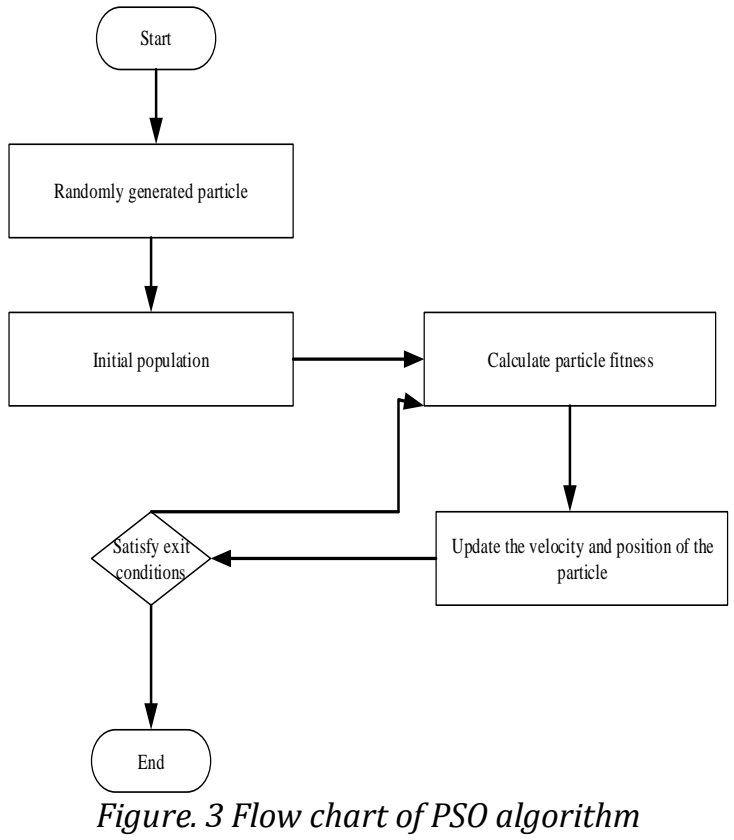

Compared with other intelligent optimization algorithms, PSO algorithm has no crossover and mutation operation, so the algorithm is simple in structure and fast in operation. However, when the basic PSO algorithm searches in the solution space, the particle oscillates in the global optimal solution. In order to solve this problem, PSO algorithm has been improved by two points. 1) The extreme disturbance factor is introduced, and equation (9) is the improved strategy.

$$
v_{i}(t+1)=0.96\left[w(t) v_{i}(t)+c_{1} r_{1}\left(r_{3} g \operatorname{best}_{i}(t)-x_{i}(t)\right)+c_{2} r_{2}\left(z \operatorname{best}(t)-x_{i}(t)\right)\right]
$$

In equation (9), $r_{3}$ is a random number greater than 0 and less than 1 , gbest is an extreme value, and the value of gbest changes with the change of $r_{3}$. This method expands the search range of particles, and then makes particles jump out of the local optimal value, and enhances the global optimization ability of particles. In the PSO algorithm, the inertia weight coefficient $\omega$ is one of the important parameters that affect the performance of the algorithm. Larger $\omega$ value can enhance the global optimization ability of PSO, and smaller $\omega$ value can enhance the local optimization ability of PSO. 2) According to the characteristics of PSO algorithm, the improved strategy is to use larger inertia weight coefficient in the initial optimization stage of PSO, and use smaller inertia weight coefficient in the later stage of PSO. Equation (10) is the expression of the proposed improvement strategy.

$$
\omega(\mathrm{t})=\omega_{\min }+\left(\omega_{\max }-\omega_{\min }\right) \cdot \cos \left(\pi t / 2 t_{\max }\right)
$$

In (10), $\omega_{\max }$ is the maximum inertia weight coefficient and $\omega_{\min }$ is the minimum inertia weight coefficient.

The relationship shown in equation (10) shows that the value of inertia weight coefficient $\omega$ is small at the beginning of the iteration of PSO algorithm, and then increases with the increase of the number of iterations. When it increases to the peak value, the value of inertia weight coefficient $\omega$ decreases with the increase of iteration times. It ensures that in the early stage of operation, the PSO algorithm performs local optimization near the particle itself. Then, the global optimization is carried out, and finally the accurate local optimization is carried out.

\subsection{PID Parameter Optimization based on Improved PSO Algorithm}

Figure 4 presents the schematic diagram of PID tuning parameters based on the improved PSO. The control of PID is mainly to optimize PID three scale factor parameters $K_{P}, K_{\mathrm{i}}$ and $K_{\mathrm{d}}$. 


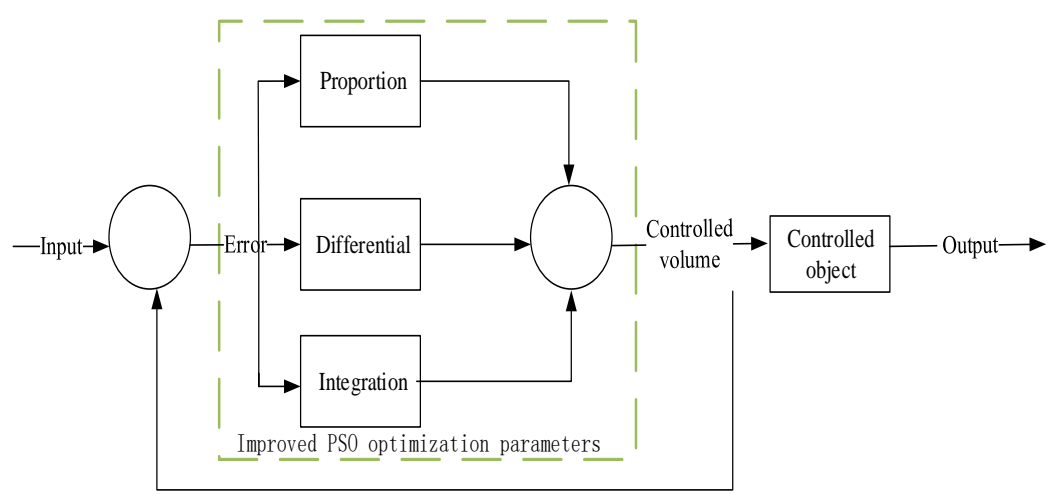

Figure 4: Parameter tuning principle of improved PSO algorithm

Figure 5 shows the process of PSO algorithm optimizing PID parameters.

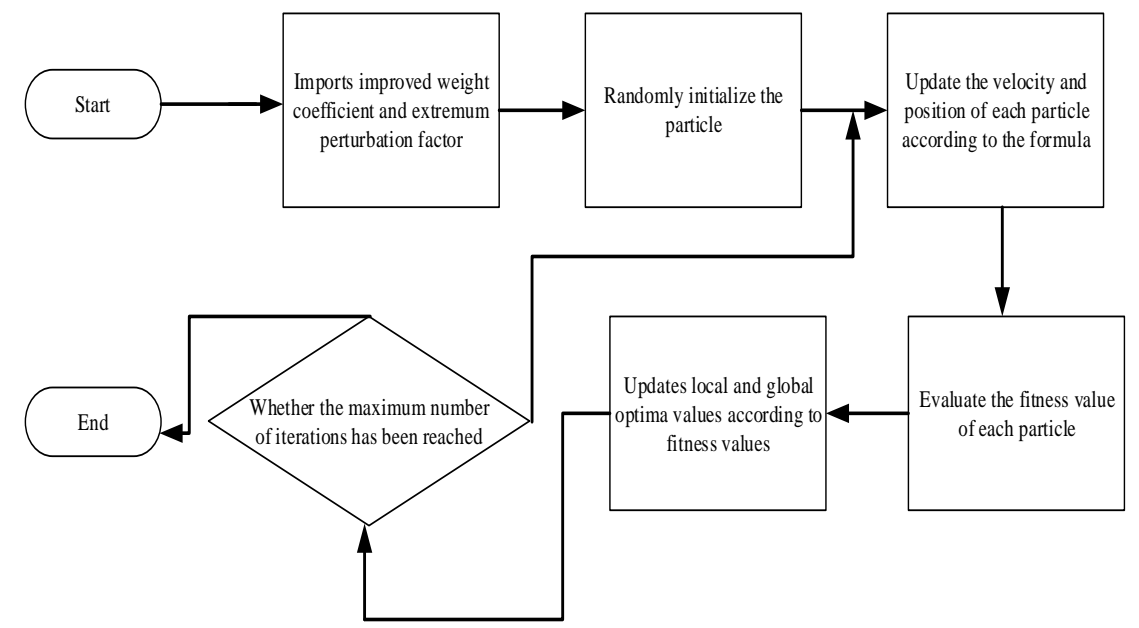

Figure 5: Flow chart of PSO algorithm optimizing PID parameters

As shown in Figure 5, the optimization process of PSO algorithm can be divided into six steps.

1) The improved weight coefficient, learning factor and extreme disturbance factor of PSO algorithm are introduced.

2) Particles are randomly initialized.

3) The corresponding equation is used to update the velocity and position of each particle.

4) The fitness of each particle is evaluated.

5) According to the fitness value, the global optimal value and local optimal value are updated.

6) Whether the number of runs of the algorithm reaches the maximum number set in advance, or whether any particles reach the global optimal position is judged.

\subsection{Experimental Parameters Environment Configuration}

The adaptive controller with PSO optimization is used to simulate the servo system. The rated power of the synchronous motor used for simulation research is $2.0 \mathrm{KW}$, the rated torque is $12 \mathrm{~N} . \mathrm{m}$, the rated current is $5 \mathrm{~A}$, the rated speed is $1400 \mathrm{r} . \mathrm{min}^{-1}$, the direct axis inductance $L_{\mathrm{d}}$ is $5.64 \mathrm{Mh}$, and the quadrature axis inductance is $8.76 \mathrm{Mh}$.

\section{Simulation Study 3.1 PID Parameter Change Test}

Figure 6 shows the change curve of PID parameters optimized by PSO algorithm.

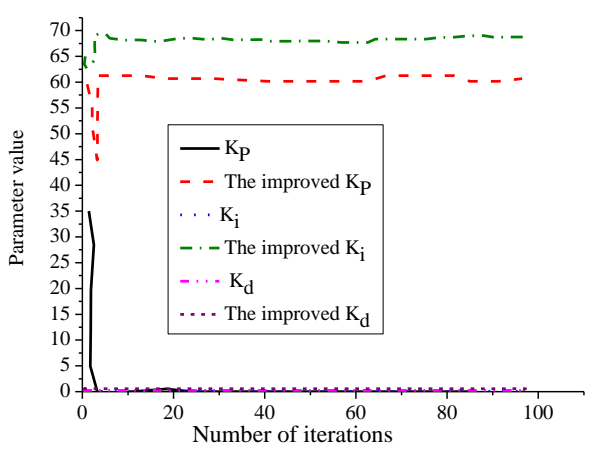

Figure 6: PID parameter change test 
Figure 6 shows that after 12 iterations, the optimal value of parameter $K_{\mathrm{i}}$ is found. After three iterations, the optimal value of parameter $K_{\mathrm{d}}$ is found.

After 18 iterations, the optimal value of parameter $K_{\mathrm{i}}$ is found. Compared with the PID parameters without the optimization of the improved PSO algorithm, the PID parameters optimized by the improved PSO algorithm can find the optimal value of the algorithm more quickly.

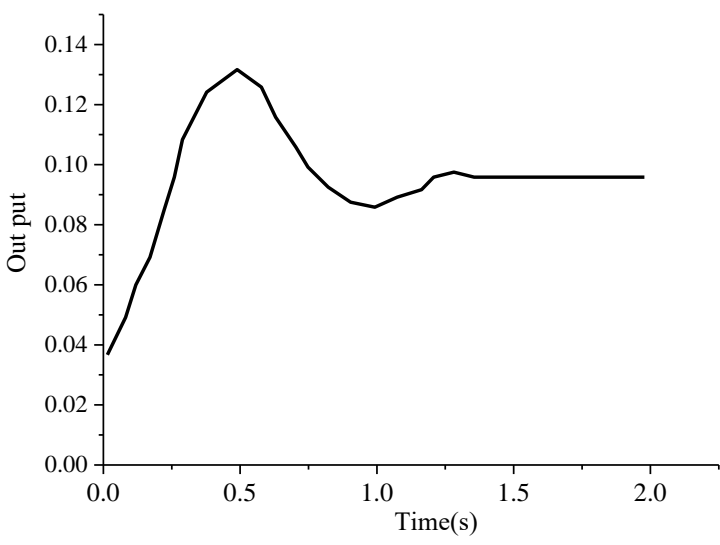

(a)

\subsection{Step Response Test of System under No Load}

Figure 7(a) shows the step response curve of the system under the PID parameter control without the optimization of the improved PSO algorithm under no load condition.

Figure 7(b) shows the step response curve of the system under PID parameter control after the improved PSO algorithm optimization under no load condition.

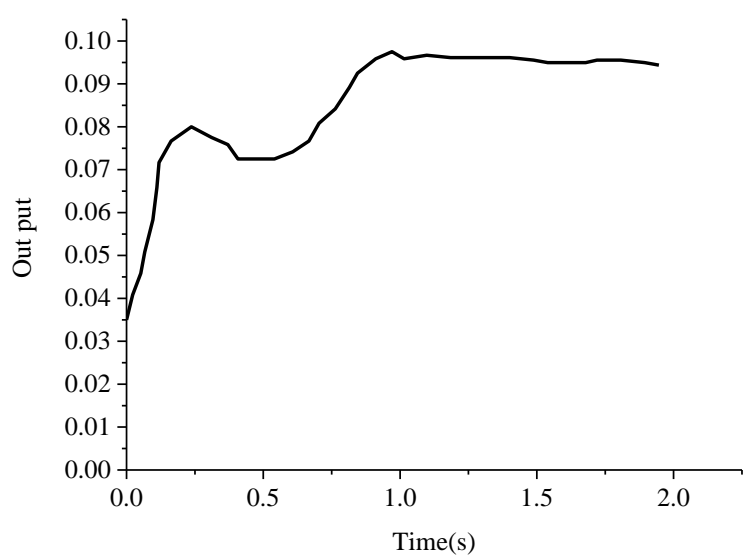

(b)

Figure 7: Step response test results of the system under no load condition ((a) response curve of PSO optimization system without optimization (no load) (b) response curve of improved PSO algorithm optimization system (no load))

Figure 7 shows that compared with the PID parameters system not adjusted by the improved PSO algorithm, the system of PID parameters adjusted by the improved PSO algorithm has faster convergence speed, higher accuracy and smaller error, which is more in line with the actual production requirements.

\subsection{Step Response Test of System under Normal Condition}

Figure 8 shows the step response test results of the system under normal conditions.

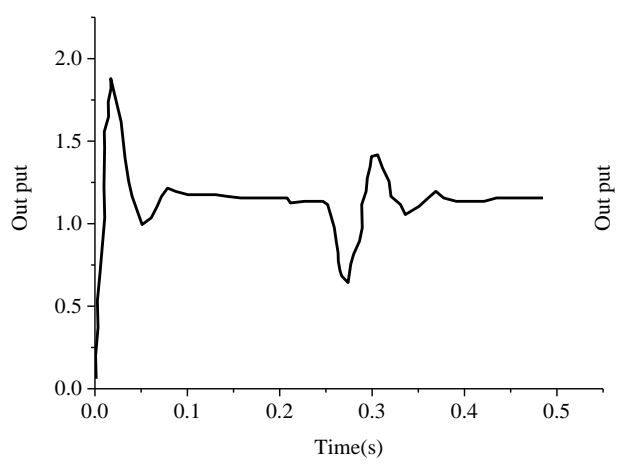

(a)

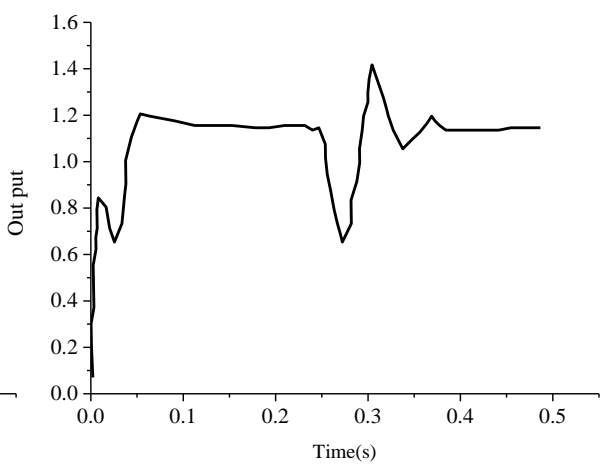

(b)

Figure 8: Test results of step response of system under normal conditions ((a) response curve of the system not optimized by the improved PSO algorithm (normal condition) (b) response curve of the system optimized by the improved PSO algorithm (normal condition))

The system step response test results in Figure 8 show that the overshoot of the system is reduced, the regulation time is shortened and the robustness is enhanced by using the PID parameter scheme 
adjusted by PSO algorithm. Thus, the correctness of the optimized PID parameters can be illustrated.

\subsection{Algorithm Comparison Test}

The PID parameters obtained by the improved PSO algorithm, crowd search algorithm (SOA), PSO optimization algorithm and GA simulation are substituted into the motor transfer equation, and the corresponding model is established.

MATLAB is used to simulate it, so as to get the comprehensive output step response curve and the comprehensive output step response error curve of the algorithm, as shown in Figure 9(a) and Figure 9(b).

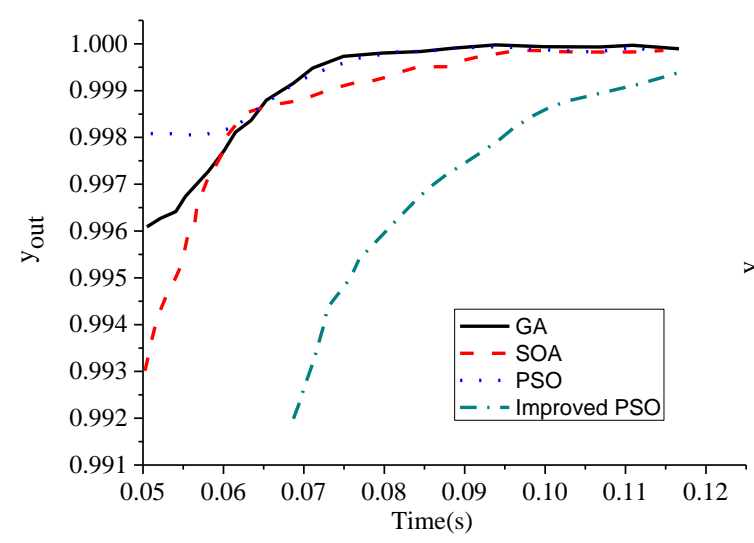

(a)

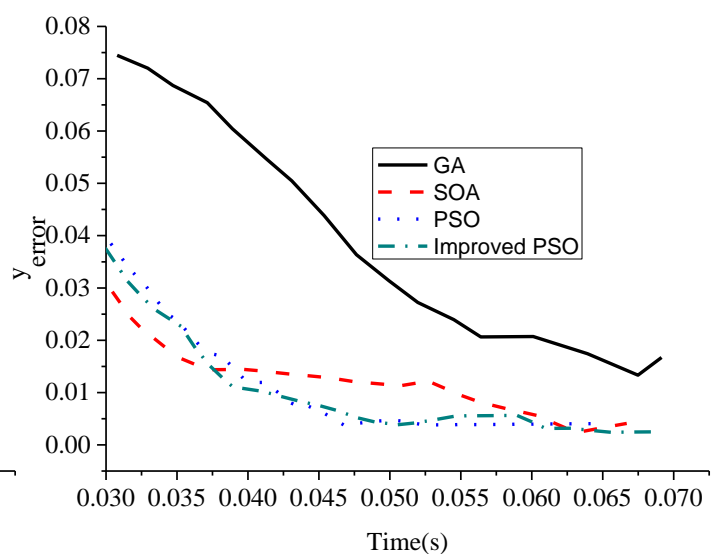

(b)

Figure 9: Comprehensive output step response curve and the comprehensive output step response error curve ((a) comprehensive output step response curve, (b) comprehensive output step response error curve))

The experimental results in Figure 9 show that PSO algorithm, SOA, optimized improved PSO optimization algorithm and GA all have good global search characteristics, and the above algorithms can get the optimization results of PID parameters. However, for the system which uses GA algorithm to optimize the index, the adjustment time of the system to the stable error is longer than that of other algorithms, and the oscillation of the transition time is severer. The PID parameters of the system optimized by the improved PSO algorithm are obviously better than those optimized by other algorithms. The adjustment time is short and the overshoot is 0 . Therefore, the PSO algorithm is the best among these algorithms.

\section{Discussion}

The PID parameter values obtained by the improved PSO algorithm are compared with those of SOA proposed by Tariq (2020) [30] and GA proposed by Guo et al. (2020) [31]. The results show that the value of $K_{P}$ is $0.040, K_{\mathrm{i}}$ is 64.321 , and $K_{\mathrm{d}}$ is 0 by SOA simulation; the value of $K_{P}$ is $0.2405, K_{\mathrm{i}}$ is 67.321, and $K_{\mathrm{d}}$ is 0 by GA simulation; the value of $K_{P}$ is $0.0005, K_{\mathrm{i}}$ is 61.311 , and $K_{\mathrm{d}}$ is 0 by optimized PSO algorithm simulation. Optimizing PID parameters through PSO algorithm can more quickly find the best value than other algorithms.

The optimization results of PSO, SOA and GA are compared. The optimization results of the control system are evaluated by the delay time, adjustment time and peak time. The evaluation results show that the delay time of the improved PSO algorithm is short, and it can be used in the system with general stability but high speed. The delay time of the original PSO algorithm is moderate, so it can be used in the system which has the requirements of smooth performance and fast performance. SOA and GA are suitable for the system with low requirements. In reality, most of the systems have general stability but high speed, so compared with other PID parameters optimized by other algorithms, the PID parameters optimized by the algorithm have a wider range of application.

\section{Conclusion}

The performance of CNC servo system is an important factor affecting the precision index of CNC machine tools. In order to get high performance servo system, it can be improved from two aspects. On the one hand, the servo motor with better performance or the hardware actuator matching it can be selected. The second is to use better control methods. 
This exploration is to study the machining control technology of machine tools from the second aspect. Therefore, the improved PSO algorithm is optimized in two points for the requirement of high precision of CNC machine tools. The first point is to introduce the corresponding equation to adaptively adjust the inertia weight of PSO algorithm. The second point is to increase the random property of particles in PSO operator by adding the extreme perturbation operator. Then, the PID parameters of servo system in CNC machine tool are adjusted by PSO algorithm, and the simulation experiment is carried out for the CNC machine tool with PID parameter adjustment. The experimental results show that the overshoot of PID parameter system optimized by PSO algorithm is reduced, adjustment time is reduced and the robustness of the system increases. Therefore, the PID parameter optimization algorithm of the servo system of CNC machine tool has achieved the expected effect.

However, the proposed algorithm also has some shortcomings. Only the improvement of PSO algorithm is made, and only the influence of inertia weight coefficient on PSO performance is considered. In the next step, PSO algorithm should be further studied and improved, and other intelligent algorithms will be considered to optimize PID parameters of servo system of CNC machine tools.

\section{Acknowledgment}

This work was supported by the quality engineering of Anhui Province (project number: 2019jyxm0839).

\section{References}

[1] Chu Y. H., Yeh S. S. (2019) Using power spectral density analysis of accelerometermeasured signals to adjust CNC machine tool cornering motion control parameters. Engineering Letters, 27(1), 166-174.

[2] Wang J., Deng X. (2019) Detection of spindle thermal state accuracy of vertical CNC machine tool. International Journal of Engineering Systems Modelling and Simulation, 11(2), 43.

[3] Tian H., Dong W., Xu Y, et al. (2021) Research on parameter adjustment method of servo controller based on genetic algorithm. Journal of Physics: Conference Series, 1786(1), 012056.

[4] Yue H. T., Guo C. G., Li Q, et al. (2020) Thermal error modelling of CNC milling machining spindle based on an adaptive chaos particle swarm optimization algorithm. Journal of the Brazilian Society of Mechanical Sciences and Engineering, 42(8), 1-13

[5] Vorkapi N., Ivanovi S., Dimi Z. (2020) Development of an educational 3-axis CNC machine tool for rapid prototyping with two translational and one rotary axis. Tehnika, 75(6), 725-732.

[6] Yang H., Wang Z., Zhang T, et al. (2020) A review on vibration analysis and control of machine tool feed drive systems. International Journal of Advanced Manufacturing Technology, 107(1-2), 1-23.

[7] Chang E. C. (2018) Research on AC Power Conditioning Control Technology for Ultraprecision Machining of Steel Materials. IOP Conference Series Materials Science and Engineering, 378(1), 012019.

[8] Grinyak V. M., Pashin S. S. (2020) Control of the Vessel Course using of PID-Regulator under Parametric Uncertainty. IOP Conference Series Earth and Environmental Science, 459, 022011.

[9] Luo Z., Peng B., Xiao Q, et al. (2018) Thermal Error Test and Intelligent Modeling Research on the Spindle of High Speed CNC Machine Tools. Iop Conference, 322, 072052.

[10] Jiang X. N., Sun Y. H., Xie X. H. (2018) Research on the NC Machining and Simulation for Spiral Bevel Gears of Half-Spread-Out Helix Modified Roll. Materials Science Forum, 939, 63-72.

[11] Zhou H., Hu P., Tan H, et al. (2018) Modelling and compensation of thermal deformation for machine tool based on the real-time data of the CNC system. Procedia Manufacturing, 26, 11371146.

[12] Chen H. H., Meng F. J., Zhang D. S, et al. (2021) Research on machining technology of complex structure parts of high-speed train body. Journal of Physics Conference Series, 1721, 012035.

[13] Zhao C., Cao G., Ding H, et al. (2021) Research on Intelligent Recognition and Control Device of Aviation Line Number. Journal of Physics: Conference Series, 1754(1), 012099.

[14] Zhong X., Zhu R., Hou K, et al. (2021) Research on the control technology of self-synchronous voltage source inverter for distributed parallel system. E3S Web of Conferences, 231(4), 01006.

[15] Xu H., Tian J. (2021) Research on automatic correction method of spiral bevel gear error reversal based on single chip microcomputer. Journal of Physics: Conference Series, 1748(6), 062002.

[16] Xia T., Mu Q., Gao Y., et al. (2020) Analysis and Research on the Construction of Virtual Reality CNC Machine Tool Mode. Journal of Physics: Conference Series, 1601(4), 042018.

[17] Jiang W. (2020) Research on Error Monitoring Model of CNC Machine Tool Based on Artificial Intelligence. Journal of Physics Conference Series, $1574,012125$.

[18] Trejo-Hernandez M., Osornio-Rios R. A. (2018) Tool-Wear Estimation in Cnc Machine Based On 
Fusion Vibration-Current and Neural Network. Journal of Scientific \& Industrial Research, 77(12), 688-691.

[19] Merghache S. M., Hamdi A. (2020) Numerical evaluation of geometrical errors of three-axes CNC machine tool due to cutting forces-case: milling. The International Journal of Advanced Manufacturing Technology, 111(5), 1683-1705.

[20] Yadav A. K., Gaur P. (2020) Modified IMC Technique for Nonlinear Uncertain Milling CNC Machine Tool System. Arabian Journal for Science and Engineering, 45(3), 2065-2080.

[21] Hwang Y. L., Ta T. N. (2020) Uncertainty Analysis of CNC Machine Tools Based on Monte Carlo Method. Applied Mechanics and Materials, 900, 9-13.

[22] Li J., Liang J., Chen G, et al. (2020) Research on Key Control Technology of Intelligent Rolling Contact Fatigue Test Facility. Journal of Control Science and Engineering, 2020(1), 1-11.

[23] Yan Y., Jiang W., Zou D, et al. (2020) Research on mechanism configuration and coordinated control for power distribution network live working robot. Industrial Robot, 47(3), 453-462.

[24] Tariq Z., Abdulrazaq A., Ghazi S. S. (2020) Sustainability Modeling Approach on Remanufacturing Conventional Lathe into CNC Machine Tool. Journal of Applied Science and Technology, 39(23), 1-30.
[25] Turhan M. H., Tseng G. W. G., Erkorkmaz K, et al. (2020) Dynamic model identification for CNC machine tool feed drives from in-process signals for virtual process planning. Mechatronics, 72, 102445.

[26] Ji Q., Li C., Zhu D, et al. (2020) Structural design optimization of moving component in CNC machine tool for energy saving. Journal of Cleaner Production, 246(Feb.10), 118976.1-118976.15.

[27] Yuksel E., Emre zlü., Oral A, et al. (2020) Design and Analysis of a 5-Axis Gantry CNC Machine Tool. MATEC Web of Conferences, 318(2), 01019.

[28] Abullah Z. T. (2020) Conventional Lathe Remanufacturing into CNC Machine Tool Uncertainty Modeling Approach. Journal of Applied Science and Technology, 39(23), 97-133.

[29] Vorkapi N., Ivanovi S., Dimi Z. (2020) Development of an educational 3-axis CNC machine tool for rapid prototyping with two translational and one rotary axis. Tehnika, 75(6), 725-732.

[30] Tariq Z. (2020) Sustainability Modeling of Conventional Milling Machine Remanufactured CNC Machine Tool Upgraded. Current Journal of Applied Science and Technology, 39(25), 197224.

[31] Guo J., Ma S., Zhang X., et al. (2020) Research on CNC Machining Technology of the Upper Shell of Electro-hydraulic Servo Valve. Journal of Physics Conference Series, 1635, 012016. 